\title{
Photoredox-catalyzed intermolecular radical addition to allenamides: a complementary approach to conjugated $\mathbf{N}$-acyliminium formation.
}

\author{
Olusesan K. Koleoso, ${ }^{a, b}$ Matthew Turner, ${ }^{a}$ Felix Plasser ${ }^{a}$ and Marc C. Kimber*a
}

${ }^{a}$ School of Science, Department of Chemistry, Loughborough University, Loughborough, LE11 3TU, UK.

Email: M.C.Kimber@lboro.ac.uk

${ }^{b}$ Department of Pharmaceutical Technology, Moshood Abiola Polytechnic, Abeokuta, Nigeria.

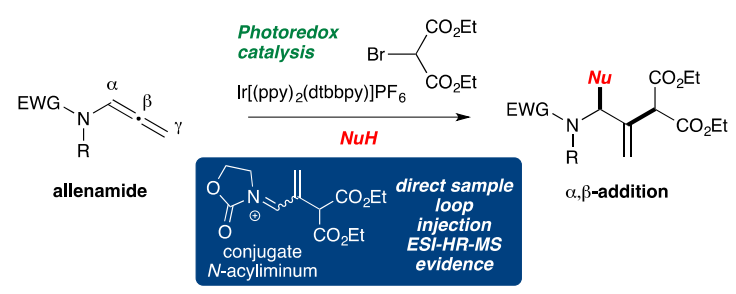

An intermolecular radical addition, using photoredox catalysis, to allenamides is reported. This transformation synthesizes $\boldsymbol{N}$-acyl$N^{\prime}$-aryl- $N, N^{\prime}$-allylaminals, and proceeds by a conjugated $\boldsymbol{N}$ acyliminium intermediate, that previously, has only been generated by electrophilic activation methods. The radical adds to the central carbon of the allene giving a conjugated $\mathrm{N}$ acyliminium, that undergoes nucleophilic addition by arlyamines and alcohols.

Allenamides (scheme $1, \mathbf{1}$ ) and their congeners have attracted considerable attention over the past 15 years due to their characteristic reactivity profiles. ${ }^{1}$ The reactivity that an allenamide can display is distinct from a traditional allene due to the presence of an amide unit attached at the $\alpha$-carbon. This substituent can donate electron density into the allene, principally onto the central $\beta$-carbon, that can be harnessed in subsequent chemical transformations leading to regiochemical confidence in the resulting products (scheme 1).

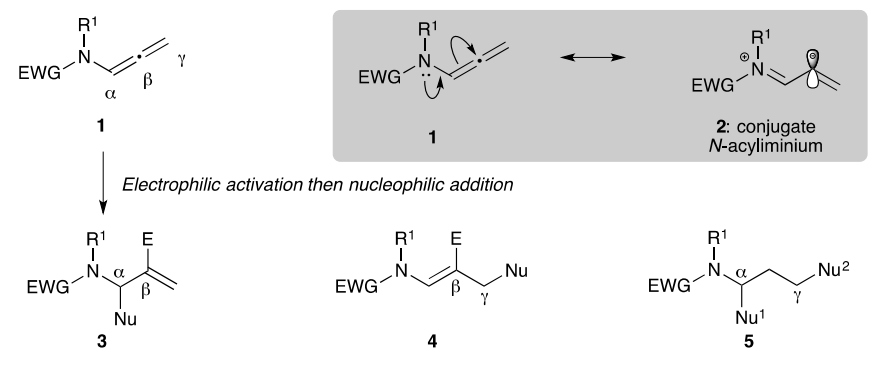

Scheme 1. Electrophilic activation of allenamides.

Importantly, this unique reactivity has led to the development of a number of innovative transformations, including cycloadditions, ${ }^{2}$ intramolecular cyclisations and intermolecular addition reactions, ${ }^{3}$ as well as the use of the allenamide building block in natural product synthesis. ${ }^{1 a}$

Addition reactions of allenamides, which can also encompass intramolecular cyclisations, are typically promoted by the electrophilic activation of the $\beta$-carbon of the allenamide. This can be achieved using various electrophilic methods, including the use of a Brönsted acids, ${ }^{3 f, 4}$ halogenation sources, $3 \mathrm{~g}, 3 \mathrm{3i,5}$ by means of oxidation ${ }^{4 b, 6}$ or by the use of transition metal such as
$\mathrm{Au}(\mathrm{I}) \cdot{ }^{2 d, 3,7}$ The reaction of the allenamide with an electrophilic source promotes the formation of a conjugated $\mathrm{N}$-acyliminium $(2)^{8}$ that subsequently undergoes an addition reaction with a suitable nucleophile (scheme 1). Significantly, while the electrophilic activation of allenamides is very well developed, the foundation of all these transformations is the formation of the key conjugated $\mathrm{N}$-acyliminium species 2 . Given the importance of the allenamide building block we sought a new synthetic methodology that could generate the conjugated $\mathrm{N}$ acyliminium 2, that would not be reliant on electrophilic activation (scheme 2 ).

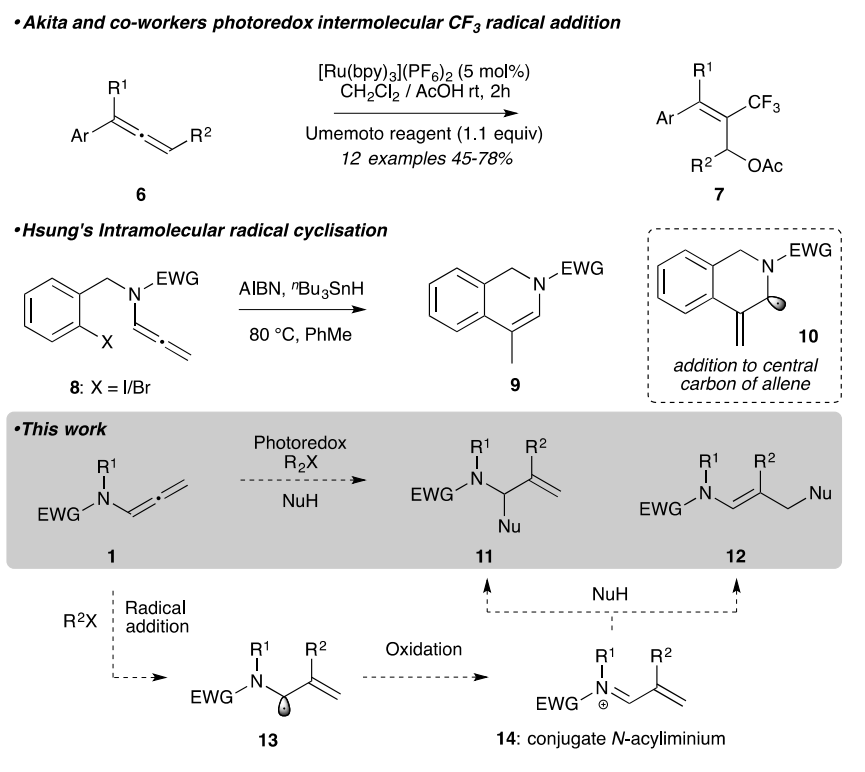

Scheme 2. The planned intramolecular radical addition to allenamides generating the conjugated $N$-acyl iminium 14

In principle, a new method for its generation could greatly enhance the value of the allenamide building block, as well as potentially unlocking new chemical reactivity yet unseen in the context of electrophilic activation. We envisaged that a route to the conjugated $\mathrm{N}$-acyliminium could be achieved via an intermolecular addition of an electrophilic radical to an allenamide (1) followed by an oxidation process on the 
subsequently formed radical (scheme 3 ). The thought process behind this approach is based on three fundamental observations; (i) Akita and co-workers disclosure on the photoredox-catalyzed oxytrifluoromethylation of allenes (6) to give 2-trifluoromethylated allyl acetates (7); 9 (ii) that intramolecular radical cyclization of allenamides have been reported by Hsung and co-workers, where the radical adds principally to the central carbon of the allene (10);10 and (iii) the photoredox-catalysed addition of radicals to enamides reported by Masson, ${ }^{11 a-d}$ and more recently by our own laboratory in the synthesis of valuable $N, N^{\prime}$-aminals. ${ }^{11 \mathrm{e}}$

We began our study by applying the effective photoredox conditions used in the addition of amine nucleophiles to enamides. ${ }^{11 \mathrm{e}}$ Employing these well-developed reaction conditions, using diethyl bromomalonate 18, 4-anisidine 16 as the amine nucleophile, and allenamide $\mathbf{1 5}$ we were able to isolate the $N$-acyl- $N^{\prime}$-aryl- $N, N^{\prime}$-allylaminal 19 as the sole identifiable product in $54 \%$ yield.
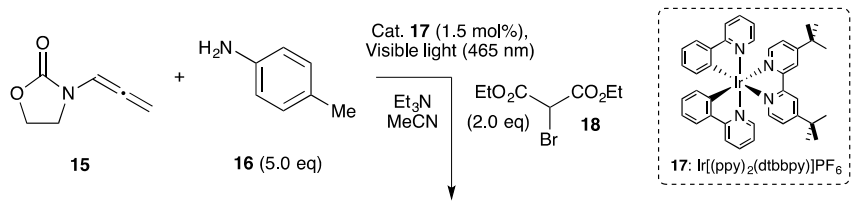

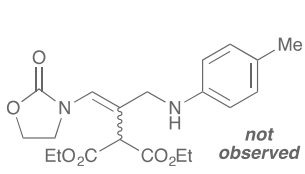

20

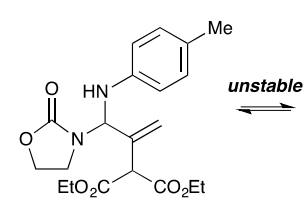

$19,54 \%$

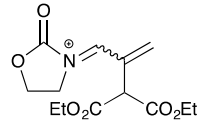

$14 a$
Scheme 3. Photoredox Ir-catalysed intermolecular addition of bromide 18 aniline $\mathbf{1 6}$ to allenamide $\mathbf{1 5 .}$

Although all of the starting allenamide 15 was consumed within the reaction, the isolated chemical yield reflects the challenging isolation of the product given its instability (a similar instability profile was observed in the $N$-acyl- $N^{\prime}$-aryl$N, N^{\prime}$-aminals derived from enamides); 11 e however, to our knowledge no comparable $N$-acyl- $N^{\prime}$-aryl- $N, N^{\prime}$-allylaminal analogues have been reported to date. ${ }^{12}$ The evidence for the formation of 19 was the appearance of the methylene protons in ${ }^{1} \mathrm{H} \mathrm{NMR}$ at $\delta 5.46(\mathrm{~d}, J=1.6 \mathrm{~Hz}, 1 \mathrm{H})$ and $\delta 5.45(\mathrm{~d}, J=2.0 \mathrm{~Hz}$, $1 \mathrm{H})$ ppm, respectively. Crucially, it is apparent that using the photoredox conditions described in scheme 3 , the aniline nucleophile adds primarily at the $\alpha$-position of the allenamide 15; this is in contrast to the archetypal electrophilic activation modes where comparable nucleophiles add to the $\gamma$ position. ${ }^{8 a, c, d}$

An examination of the allenamide unit under these conditions is shown in scheme 4 , and the 6 allenylamides/sulfonamides (15, 21-25) were prepared using known conditions. ${ }^{13}$ The allenamides derived from pyrrolidinone (21), piperidinone (22) and oxazolidinone (15) with 2,4-dimethylaniline all performed adequately in this reaction giving the their $N, N^{\prime}$-allylaminal products $\mathbf{2 6}, \mathbf{2 8}$ and $\mathbf{2 8}$, respectively. The isolated yields once again reflected the sensitivity of the $N, N^{\prime}$-allylaminal functional group. The aminosulfonyl allenyl $\mathbf{2 3}$ failed to provide any discernable product, with only a complex mixture, as identified by ${ }^{1} \mathrm{H} N M R$, being isolated. Significantly, in the ${ }^{1} \mathrm{H}$ NMR spectra of this complex mixture we observed complete fragmentation of the sulfonamide unit. Two chiral allenamides (24 and 25) were exposed to the photoredox conditions with 2,4-dimethylaniline, and it was observed that the predominant product in each case was Z-30 and Z-31, respectively, which presumably result from $\gamma$-addition of the nucleophile. This was confirmed by ${ }^{1} \mathrm{H}$ NMR NOE analysis of Z-30, where an enhancement between the enamide proton and the methylene proton were observed, as shown in scheme 4.

Given our interest in the $N, N^{\prime}$-aminal functionality, ${ }^{11 \mathrm{e}}$ we also explored variation of the arylamine nucleophile. 2,4Dimethylaniline, 2-anisole, 2- trifluoromethoxyaniline and 3,5ditrifluoromethylaniline were all effective in this transformation, giving their labile $N, N^{\prime}$-allylaminal products (32 to 35 ) in moderate to good isolated yields.

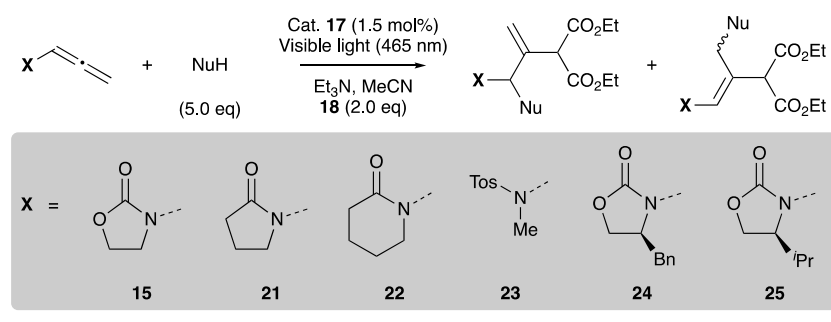

(a)<smiles>C=C(C(C(=O)OCC)C(=O)OCC)C(Nc1ccc(C)cc1[N+](=O)[O-])N1CCCC1=O</smiles><smiles>C=C(C(C(=O)OCC)C(=O)OCC)C(Nc1ccc(C)cc1C)N1CCCCC1=O</smiles><smiles>C=C(C(OCC)C(=O)OCC)C(Nc1ccc([N+](=O)[O-])cc1[N+](=O)[O-])N1CCOC1=O</smiles>

$26,54 \%$<smiles>[Y5]N(P)C(Nc1ccc(C)cc1[N+](=O)[O-])C(=C)C(OCC)C(=O)OCC</smiles>

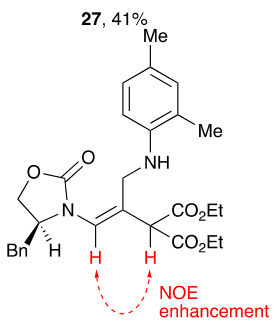

$28,57 \%$

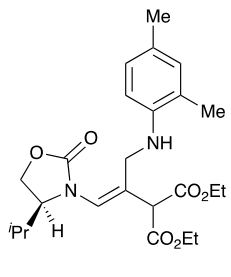

$29,0 \%$

$Z-30,41 \%$

$Z-31,50 \%$
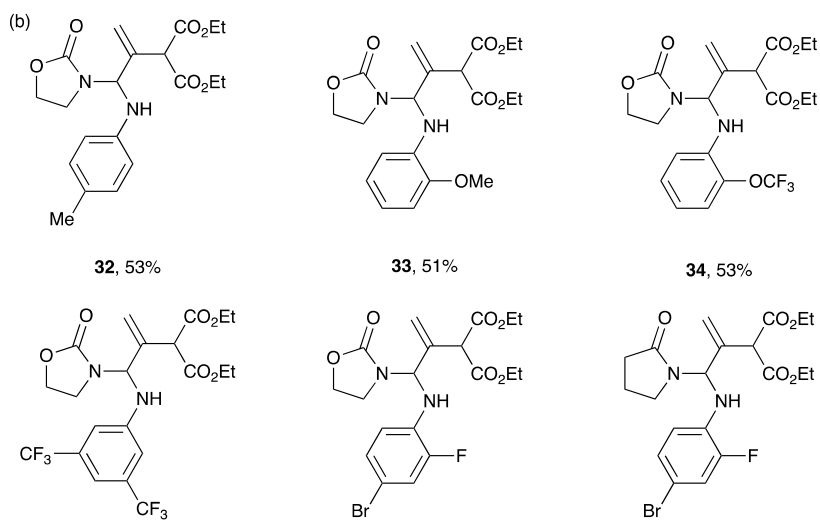

35, $45 \%$

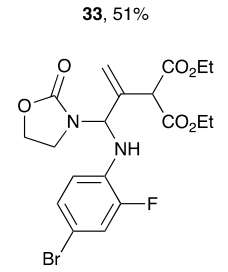

36, $46 \%$

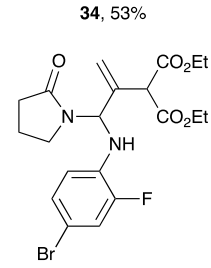

$37,42 \%$ (c)
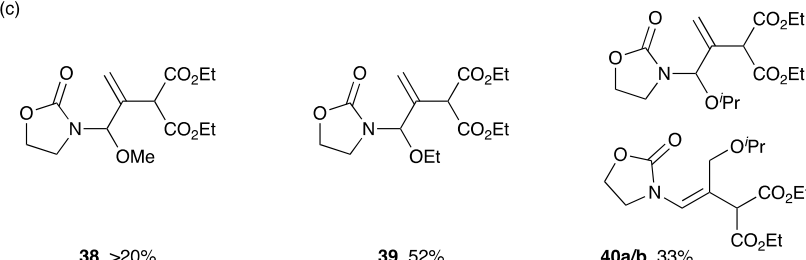

$38,>20 \%$

$39,52 \%$

$40 \mathrm{a} / \mathrm{b}, 33 \%$

Scheme 4. Reaction scope (a) allenamide; (b) arylamine nucleophile; (c) alcohol nucleophile. 
4-Bromo-2-fluoroaniline was also examined as a nucleophile, as we had previously shown this to be an effective aniline platform for developing Linezolid analogues, and this delivered two $N, N^{\prime}$-allylaminals 36 and 37 , respectively. Masson had previously explored oxygen nucleophiles in their photoredoxcatalysed addition to enamides. ${ }^{11 c}$ Consequently the use of excess methanol provided the addition product $\mathbf{3 8}$, resulting from $\alpha$-addition, in a modest isolated yield. The stability of product 38 was marginal, but an improved stability of the $\mathrm{N}, \mathrm{O}^{\prime}$-allyl product was observed when ethanol was used as the nucleophile giving product 39 in 52\% isolated yield. In contrast, isopropanol gave an inseparable mixture of the $\alpha$ - and $\gamma$ addition products, $\mathbf{4 0 a} / \mathbf{b}$ in $33 \%$ isolated yield.

A proposed mechanism ${ }^{11 c}$ for this transformation is described in scheme 5(a). Exposure of 18 to the photoredox conditions generates an electrophilic radical $R^{\circ}$, that subsequently adds to the $\beta$-carbon of the allenamide $\mathbf{1}$ providing $41 .{ }^{11}$ The calculated HOMO of allenamide 15 is shown in scheme $5(b)$, signifying the increased nucleophilicity at this $\beta$-carbon. Radical $\mathbf{4 1}$ is stabilized, but is further oxidized under the photoredox conditions, ${ }^{11 a-c}$ giving rise to two iminium stereoisomers $Z-\mathbf{4 2}$ and $E-\mathbf{4 2}$, respectively, with each of these iminium stereoisomers existing in two further conformers designated $E-\mathbf{4 2}$ ' and Z-42'.
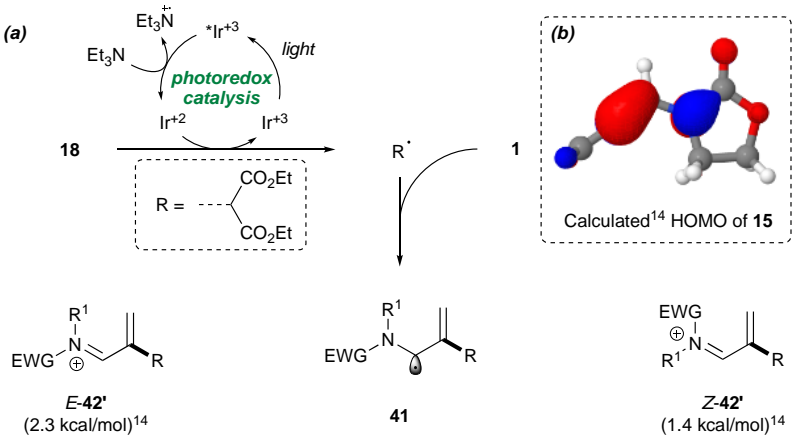

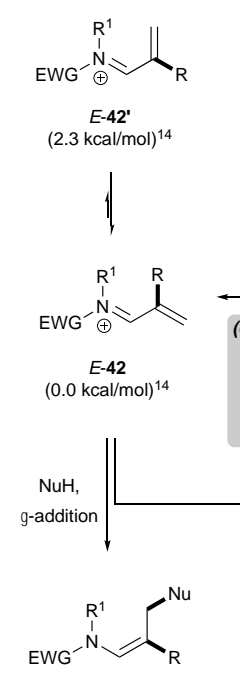

44

$$
\underbrace{\mathrm{EWG}}_{\substack{Z-42^{\prime} \\(1.4 \mathrm{kcal} / \mathrm{mol})^{14}}}
$$
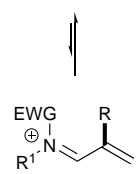$$
z-42
$$$$
(5.6 \mathrm{kcal} / \mathrm{mol})^{14}
$$
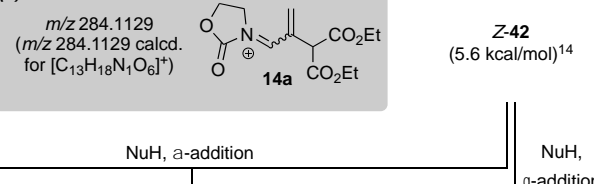

Scheme 5. (a) Postulated mechanism for the photoredox catalyzed formation of the conjugated $\mathrm{N}$-acyl iminium; (b) the calculated HOMO for allenamide 15; (c) the identification of intermediate 14 a by direct sample loop and flow injection ESI-HRMS analysis.

DFT calculations ${ }^{14}$ were performed on all four of these proposed structures, where it was observed that Z-42 was approx. $6 \mathrm{kcal} / \mathrm{mol}$ higher in energy, relative to the most stable isomer $E$-42, which was $1-2 \mathrm{kcal} / \mathrm{mol}$ lower in energy than $E$ 42' and Z-42', respectively. It is probable that E-42 and Z-42' undergoes nucleophilic addition at $\alpha$-position giving the observed $N, N^{\prime}$-allylaminal product 43. Conversely, addition of a nucleophile at the $\gamma$-position of $E$-42 gives the observed $Z$ enamide 44; and addition at the $\gamma$-position of $Z$-42' gives the same observed Z-enamide $\mathbf{4 4}$ after $\mathrm{C}-\mathrm{N}$ bond rotation.

To support this mechanistic hypothesis we used ESI-MS to identify the formation of the key conjugated $\mathrm{N}$-acyl iminium 14a. The addition of $\mathbf{1 8}$ to allenamide $\mathbf{1 5}$ under the Ir-catalyzed photoredox conditions in the presence of 4-bromoaniline was monitored by direct sample loop and flow injection analysis by ESI-HRMS. ${ }^{15}$ After 5 minutes we observed a peak at $\mathrm{m} / \mathrm{z}$ 284.1129 that corresponded satisfactorily to the expected iminium complex 14a ( $\mathrm{m} / \mathrm{z}$ 284.1129: calcd for $\left.\left[\mathrm{C}_{13} \mathrm{H}_{18} \mathrm{~N}_{1} \mathrm{O}_{6}\right]^{+}\right)$. This peak persisted at 15, 30, 60 and 120 min time intervals, respectively, further supporting the formation of the conjugated $\mathrm{N}$-acyl iminum.

In conclusion, we have demonstrated the first intermolecular addition of a radical, generated under photoredox conditions, to an allenamide. The addition of the radical occurs at the central carbon of the allene, giving a conjugated $\mathrm{N}$-acyl iminium intermediate after subsequent oxidation. The conjugated $\mathrm{N}$-acyl iminium can undergo nucleophilic addition with an arylamine or alcohol at the $\alpha$-or $\gamma$-position, with the regioselectivity being controlled by steric factors. Significantly, the formation of the key conjugated $\mathrm{N}$ acyl iminium intermediate using these photoredox conditions can be seen as complementary to the well-developed electrophilic activation modes of allenamides. Further exploration of this radical addition to allenamides, and an exploration of the reactivity of the conjugated $N$-acyl iminium intermediate using these new conditions are currently being investigated.

We gratefully acknowledge financial support from Loughborough University and the Tertiary Education Trust Fund (TETFund) Abuja, Nigeria (O.K.K.).

\section{Notes and references}

1 For reviews see (a) T. Lu, Z. Lu, Z. -X. Ma, Y. Zhang and R. P. Hsung, Chem. Rev. 2013, 113, 4862; (b) J. L. Mascareñas, I. Varela and F. López, Acc. Chem. Res. 2019, 52, 465; (c) P. Chandrasekar, Coord. Chem. Rev. 2019, 392, 1; (d) P. E. Standen and M. C. Kimber, Curr. Opin. Drug. Dis. Dev. 2010, 13, 645.

2 For recent examples see (a) F. Yan, H. Liang, B. Ai, W. Laing, L. Jiao, S. Yoa, P. Zhoa, Q. Liu, Y. Dong and H. Liu, Org. Biomol. Chem. 2019, 17, 2651; (b) X. Zhong, Q. Tang, P. Zhou, Z. Zhong, S. Dong, X. Liu and X. Feng, Chem. Commun. 2018, 54, 10511; (c) J. N. Ayres, M. T. J. Williams, G. J. Tizzard, S. J. Coles, K. B. Ling and L. C. Morrill, Org. Lett. 2018, 20, 5282; (d) N. De, C. E. Song, D. H. Ryu and E. J. Yoo, Chem. Commun. 2018, 54, 6911; (e) W. -F. Zheng, G. -J. Sun, L. Chen and Q. Kang, Adv. Synth. Cat. 2018, 360, 1790.

3 For recent examples see (a) J. Zhang, P. -C. Zhang and J. Han, Angew. Chem. Int. Ed. 2019, 58, 11444; (b) V. Pirovano, E. Brambilla, S. Rizzato, G. Abbiati, M. Bozzi and E. Rossi, J. Org. Chem. 2019, 84, 5150; (c) J. Cui, L. Meng, X. Chi, Q. Liu, P. Zhao, D. -P. Zhang, L. Chen, X. Li, Y. Dong and H. Liu, Chem. Commun. 2019, 55, 4355; (d) S. Banerjee, B. Senthilkumar and N. T. Patil, Org. Lett. 2019, 21, 180; (e) J. An, L. Lombardi, S. Grilli and M. Bandi, Org. Lett. 2018, 20, 7380; (f) K. Yang, X. Bao, S. Liu, J. Qu and B. Wang, Eur. J. Org. Chem. 2018, 46, 6469; (g) Y. Li, G. Luo, X. Xiao and Z. G. Zhao, New. J. Chem. 2018, 42, 16940; (h) J. Hédouin, C. Schneider, I. Gillaizeau and C. Hoarau, Org. Lett. 2018, 20, 6027; (i) X. Yuan, X. J. A. T. R. H. Man, X. -X. Li and Z. -G. Zhao, Tetrahedron 2018, 74, 5674 . 
4 (a) B. Yang, X. Zhai, S. Feng, D. Hu, Y. Deng and Z, Shao, Org. Lett. 2019, 21, 330; (b) L. Villar, U. Uria, J. I. Martinez, L. Prieto, E. Reyes, L. Carrillo and J. L. Vicario, Angew. Chem. Int. Ed. 2017, 56, 10535; (c) X. Yang and D. F. Toste, Chem. Sci. 2016, 7, 2653; (d) E. Manoni, A. Gualandi, L. Mengozzi, M. Bandini and P. G. Cozzi, RSC Adv. 2015, 5, 10546.

5 (a) H. -H. Li, X. -X. Li, Z. -G. Zhao, C. -B. Lin, T. Ma, C. -Y. Sun, B. -W. Yang and X. -L. Fu, Tetrahedron Lett. 2016, 57, 4640; (b) H. Li, X. Li, Z. Zhao, T. Ma, C. Sun and B. Yang, Chem. Commun. 2016, 52, 10167; (c) M. Noguchi, H. Okada, M. Watanabe, K. Okuda and O. Nakamura, Tetrahedron 1996, 52, 6581; (d) Y. Zhu, G. Yin, D. Hong, P. Lu and Y. Wang, Org. Lett. 2011, 13, 1024; (e) Y. Zhu, G. Yin, L. Sun, P. Lu and Y. Wang, Tetrahedron 2012, 68, 10194; (f) C. J. T. Hyland and L. S. Hegedus, J. Org. Chem. 2006, 71, 8658.

6 (a) C. Rameshkumar, H. Xiong, M. R. Tracey, C. R. Berry, L. J. Yao and R. P. Hsung, J. Org. Chem. 2002, 67, 1339; (b) H. Xiong, R. P. Hsung, C. R. Berry and C. Rameshkumar, J. Am. Chem. Soc. 2001, 123, 7174; (c) E. H. Krenske, K. N. Houk, A G. Lohse, J. E. Antoline and R. P. Hsung, Chem. Sci. 2010, 1, 387.

7 For recent examples see (a) D. C. Marcote, I. Varela, J. Fernández-Casado, J. L. Mascareñas and F. López, J. Am. Chem. Soc. 2018, 140, 16821; (b) Y. Wang, P. Zhang, X. Di, Q. Dai, Z. -M. Zhang and J. Zhang, Angew. Chem. Int. Ed. 2017, 56, 15905; (c) J. Fernández-Casado, R. Nelson, J. L. Mascareñas and F. López, Chem. Commun. 2016, 14, 2909; (d) Y. Wang, P. Zhang, Y. Liu, F. Xia and J. Zhang, Chem. Sci. 2015, 6, 5564; (e) L. Rocchigiani, M. Jia, M. Bandini and A. Macchioni, ACS. Catal. 2015, 5, 3911.

8 (a) N. H. Slater, N. J. Brown, M. R. J. Elsegood and M. C. Kimber, Org. Lett. 2014, 16, 4606; (b) S. Singh, M. R. J. Elsegood and M. C. Kimber, Synlett 2012, 565; (c) A. W. Hill, M. R. J. Elsegood and M. C. Kimber, J. Org. Chem. 2010, 75, 5406; (d) M. C. Kimber, Org. Lett. 2010, 12, 1128.

9 (a) R. Tomita, T. Koike and M. Akita, Chem. Commun. 2017 53, 4681; a single example of sulfonyl radical generated under Cu-catalysis adding to an allenamide has been reported (b) N. Lu, Z. Zhang, N. Ma, C. Wu, G. Zhang, Q. Liu and T. Liu, Org. Lett. 2018, 20, 4318.

10 L. Shen and R. P. Hsung, Org. Lett. 2005, 7, 775.

11 (a) G. Dagousset, A. Carboni, E. Magnier and G. Masson, Org. Lett. 2014, 16, 4340; For a review see: (b) T. Courant and G. Masson, J. Org. Chem. 2016, 81, 6945; (c) T. Courant, G. Masson, Chem. Eur. J. 2012, 18, 423; (d) A. Carboni, G. Dagousset, E. Magnier and G. Masson, Org. Lett. 2014, 16, 1240; (e) O. K. Koleoso, M. R. J. Elsegood, S. J. Teat and M. C. Kimber, Org. Lett. 2018, 20, 1003.

12 Given the instability of these reaction products, this and all subsequent reactions were performed on a $1.0 \mathrm{mmol}$ scale in duplicate.

13 (a) T. W. Bousfield and M. C. Kimber Tetrahedron Lett. 2015, 56, 350; also see (b) L. -L. Wei, H. Xiong, C. J. Douglas and R. P. Hsung, Tetrahedron Lett. 1999, 40, 6903.

14 DFT geometry optimisations calculations were performed at the PBEh-3c level of theory; please see the ESI.

15 (a) Y. Al-Jawaheri, M. Turner and M. C. Kimber, Synthesis 2018, 50, 2329; (b) R. Qian, H. Guo, Y. Liao, Y. Guo and S. Ma, Angew. Chem. Int. Ed. 2005, 44, 4771. 